\title{
MEMORIA E IDENTIDAD: LA ASOCIACIÓN GABRIEL / TZINZUNZAN, EN LA RUTA DE SU EVASIÓN, DE YOLANDA OREAMUNO
}

\author{
Ivonne Robles Mohs
}

\begin{abstract}
RESUMEN
El presente estudio ofrece una lectura de la compleja asociación Gabriel / Tzinzunzan y de las relaciones de ésta con la memoria y con la pérdida de la lengua española, es decir, con la reactivación de la identidad latinoamericana, que inscribe la novela de Yolanda Oreamuno; con lo cual se constituye un rico y complejo proceso de delexicalización y se le devuelve la plenitud sémica al significante tarasco, para liberar los significados neutralizados por la lengua española, por el cristianismo y por el virreinato.

Palabras clave: transgresión, heterodoxia lingüística y religiosa, proceso de delexicalización, plenitud sémica.
\end{abstract}

\begin{abstract}
The current study offers an argument concerning the complicated association Gabriel / Tzinzunzan and the relationship of this with the memory and loss of the Spanish language, that is to say, with the reactivation of the Latin American Identity, which is presented in the novel of Yolanda Oreamuno; which constitutes a rich and complex process of delexicalization which fully returnes the semic plentitude for the "tarasco" significance in order to liberate the meanings neutralized by the Spanish language, by Christianity, and by the viceroyality.

Key words: transgression, linguistic and religious heterodoxy, process of delexicalization, semic plentitude.
\end{abstract}

La novela de Yolanda Oreamuno ha sido objeto de una rica reflexión, la cual se ha sustentado con diversas perspectivas teórico-metodológicas y ha circulado, principalmente, en tres valiosos estudios: “La ruta de su evasión” de Yolanda Oreamuno, de Manuel Picado Gómez (1979), Cuando estalla el silencio. Para una lectura femenina de textos hispánicos (1992) y Espíritu en carne altiva (1997), ambos de Emilia Macaya, los cuales, en el ámbito académico, constituyen una proyección de las respectivas tesis de grado y de posgrado.

En dos de estos estudios, el análisis en torno al personaje Gabriel y sus relaciones con la palabra Tzinzunzan ha ocupado un lugar significativo. Manuel Picado (1979: 76) considera que el monólogo de Gabriel, expuesto en el capítulo veintidós de la novela, está "muy logrado"

Ivonne Robles Mohs. Profesora de la Escuela de Filología, Lingüística y Literatura. Universidad de Costa Rica. San Pedro, San José, Costa Rica. 
y que el vocablo Tzinzunzan no sólo interrumpe constantemente su discurso, sino que "actúa como un refuerzo del estado a que ha llegado su crisis próxima a resolverse en el suicidio". Emilia Macaya (1997: 178-80) refiere que la fractura del discurso patriarcal se logra por medio de la "introducción de un lúdico elemento perturbador, ese Tzinzunzan", el cual, al inicio, apenas aletea en el discurso lógico y ensimismado de Gabriel y luego llega a inundarlo todo; y que Gabriel, ya al borde de la inconciencia total y de la muerte, asume el monólogo de manera directa y "en ese abandono a la locura que antes negó, se entrega al vaivén del Tzinzunzan y del desvarío".

Así las cosas, es evidente la complejidad de la asociación Gabriel / Tzinzunzan; pero las relaciones de esta asociación con la memoria y con la pérdida de la lengua española, es decir, con la reactivación de la identidad latinoamericana, requiere una lectura específica, propósito que se sigue en este estudio.

La novela de Yolanda Oreamuno está conformada por veintitrés capítulos; en el penúltimo, o sea en el número veintidós, la instancia narrativa inscribe noventa y dos veces la palabra Tzinzunzan y, como se dijo, la asocia con Gabriel, el segundo hijo de Teresa y de Vasco Mendoza. Esta inscripción se efectúa por medio de 14 modos distintos y con diferentes tipos de letra: 1) se incorpora como un vocablo completo (Tzinzunzan); 2) divide las otras palabras y se inserta entre las respectivas partes (ninguna cosa dife Tzinzunzan rente); 3) se fragmenta y se intercala entre las otras palabras (Estoy tan bien como an Tzin tes zun igual zan que Tzin antes); 4) aparece su primera sílaba, continúa otra palabra y siguen puntos suspensivos ( Tzin antes .... ), 5) el orden de sus sílabas primera y última se altera o se invierte y se elimina la "t" inicial (Zanzinzun); 6) se incorpora entre comillas (“Tzinzunzan”); 7) la separación de las respectivas sílabas se realiza por medio de guiones (Tzin-zun-zan); 8) se introduce una " $t$ " antes de la última sílaba (Con una "t" más antes de la última sílaba); 9) se reitera tres o cuatro veces seguidas (Tzinzunzan, Tzinzunzan, Tzinzunzan); 10) la división de sus sílabas se da a través de puntos suspensivos (tzin...zun...zan); 11) en una oración, se reitera con mayúscula y con minúscula y con distintos tipos de letra intercalados (Tzinzunzan....tzinzunzan); 12) se emplea un espacio para separar cada una de sus letras (Tzinzuntzan);13) se reitera como un continuo y a la vez, en la última expresión, se invierte el orden de sus sílabas (tzinzuntzanzintzuntzanzinzun); y 14) finalmente, se reitera la incorporación como un continuo y se combina con diferentes formas de inserción: a) las sílabas se dividen por medio de un espacio, b) se separa la primera sílaba y las otras dos permanecen juntas, c) las dos primeras sílabas aparecen unidas y la tercera está separada por un espacio, y d) las dos primeras sílabas continúan juntas, pero la tercera no sólo está dividida por un espacio, sino que en ella, con excepción de la " $t$ " se da una reduplicación del resto de sus letras ( Tzinzuntzantzinzunzan tzin zun tzan tzin zuntzan tzinzun zan tzin zuntzan tzinzun tzan tzinzun tzzzaannn ) (Oreamuno: 1994: 314-37).

La compleja imbricación que se establece entre los significantes Gabriel Mendoza y Tzinzuntzan, es decir, entre los indicios onomásticos privilegiados y pertenecientes a distintos contextos culturales, configura, progresivamente, la polifonía, la intertextualidad, la ruptura de la homogeneidad y la impugnación o el descentramiento de la conquista de América y sus correlatos. Esta polifonía o descentramiento permite develar que la sistemática de la invención se configura en torno a unas oposiciones centradas alrededor de los conceptos de asimilación o de identificación y de distanciamiento; es decir, a través de la intertextualidad se establece un discurso de la identificación, que unas instancias conservadoras imponen al individuo; empero, 
ante esta represión, el texto contesta mediante la ocultación y la difracción del sentido, o sea, por los indicios, crea una contraposición o una impugnación con el primer discurso (Cros 1986: 181-99).

De conformidad con Severo Sarduy (Fernández Moreno et al. 1977: 170-2), se puede afirmar, entonces, que la evocación del significante 1492 en el amplio mecanismo de inscripción de la palabra tarasca Tzinzunzan -en catorce modalidades y en noventa y dos recurrencias-, el nombre y el apellido del personaje referido -Gabriel Mendoza- conforman una proliferación; ya que se oblitera el significante de un significado dado, por una cadena de significantes que progresa metonímicamente y que termina circunscribiendo el significante ausente, al trazar una órbita alrededor de él, órbita de cuya lectura se puede inferir.

Desde esta línea de comprensión, es posible decir que dicha proliferación connota, como se dijo, la conquista de América y con ésta sus correlatos específicos: la llegada de Cristóbal Colón en 1492, la imposición del cristianismo, por medio del nombre -Gabriel- , la instalación del primer virreinato en América, a través del apellido Mendoza, y la implantación de la lengua española; por consiguiente, la suplantación de las lenguas y de las religiones aborígenes, por medio del significante Tzinzunzan. Con Sarduy, también se puede decir que la cadena que designa el significado "conquista" enriquece la percepción de éste, a la vez que hace referencia al significante ausente, expulsado, puesto que nombrarlo sería abundar en su panoplia y ampliar el registro de su poder.

Desde esta perspectiva, la inscripción de los significantes Gabriel, Mendoza, Tzinzunzan y las diversas relaciones de tensión y de contradicción que genera, pone de manifiesto tanto la heterodoxia linguiística y religiosa como la amenaza de una ruptura del orden socio-cultural existente.

Según la tradición judeo-cristiana, Gabriel significa "fortaleza de Dios" y es el nombre del Arcángel que anuncia a la Virgen María que será la Madre de Cristo o del Salvador; además, se le considera como el guardián del tesoro celestial, el Ángel de la Redención y el mensajero supremo de Dios. De acuerdo con el ejército angélico, por medio de la tercera jerarquía -ejecutora de la voluntad divina- el cielo entra en contacto con la tierra y, precisamente, los Arcángeles son los guerreros celestes. En las representaciones pictóricas de la Anunciación se destaca, por lo general, la figura majestuosa del Arcángel, ricamente vestido, con alas muy grandes, con cetro y con corona que indican su carácter soberano y con la mano derecha en actitud de saludo y de bendición. El misterio de la Anunciación del nacimiento de Jesús a la Virgen también se asocia con la primavera (Pérez-Rioja: 1962: 60, 63 y 185).

En La ruta de su evasión, la instancia narrativa relaciona a Gabriel con la cruz, quizás el símbolo más universal de Cristo, específicamente, cuando él ingresa en la universidad y debe ser rapado como el resto de los alumnos, pero los estudiantes veteranos, con el fin de hacer más indecorosa la pelada, le dibujan, con las tijeras, sobre su cabeza, una cruz que comenzaba "en la frente, abría sus brazos en las sienes y moría en la nuca sobre el cuello de la camisa" (Oreamuno 1994: 11); de manera significativa, en la tarde, Gabriel va al barbero para que le quite la cruz y lo deje rapado como a todos los demás. Asimismo, evoca la orden arcangelical cuando la narradora básica expresa que Teresa, por su sufrimiento, su estado difuso, sus frecuentes delirios, sus crisis de asfixia y dolores, había alcanzado "una categoría arcangélica" (1994: 355); situación deplorable que ella ha vivido durante años por llegar a tener la enorme casa hipotética de sus sueños: con vastos aposentos y con anchos corredores a un jardín lleno de árboles, de pájaros y de flores, y que su hijo Gabriel reprocha con vehemencia, 
porque considera que su madre es responsable de haberla permitido. Gabriel es el consentido de Teresa, pero decide abandonar la casa para estar solo y para no mirar esa casa que lo abruma, donde solamente se oyen los pasos de su padre, a quien odia, y en la cual han crecido él y sus hermanos, quienes sólo son "Armazones sin contenido" (1994: 266).

En la tradición tarasca, Tzinzunzan significa "donde está el colibrí” (González Torres 1991: 189) y es la ciudad capital del respectivo reino, la cual se dedica a Venus en su advocación de Curita-Caheri, a quien se le representa como colibrí en su denominación como mensajero de la guerra, y donde se le da especial importancia a la práctica del sacrificio humano. Curita-Caheri o "el gran sacerdote fuego" es el nombre que también recibe Venus en su advocación de sacerdote del Sol y en su doble carácter de estrella matutina y vespertina. Según Jacques Soustelle (1956: 111-2), Venus, que nace como estrella de la mañana en oriente, después desaparece y reaparece como estrella de la tarde en occidente, simboliza la muerte y el renacimiento.

Además, es oportuno señalar que el colibrí, pájaro americano, insectívoro, de tamaño muy pequeño y pico muy largo y débil (Real Academia Española 2001: 588), por su peculiar forma de volar, o sea, por estar en continuo movimiento, por su valentía y por hibernar, es un ave de gran importancia en la cosmovisión de todos los pueblos mesoamericanos. Por ejemplo, Huitzilopochtli o "colibrí de la izquierda" es el nombre de la máxima deidad de los mexicas y, actualmente, entre los grupos mayenses, se cree que el Sol se transforma en colibrí para convertirse en amante de la Luna, según Yolotl González Torres (1991: 45); el nombre de la divinidad azteca también se traduce como "colibrí zurdo", que quiere decir "el guerrero resucitado del sur", porque el sur es el lado izquierdo del mundo y los guerreros resucitan en el cuerpo tenue y resplandeciente del colibrí (Soustelle 1956: 112-3).

Al tenor de las reflexiones de la investigadora González, resulta insoslayable destacar que la importancia del planeta Venus y su adoración parece ser una de las características relevantes de la religión mesoamericana, ya que, además de su importancia augural y de su posible relación con el tonalpohualli, por lo que es representado en muchos de los códices que contienen el calendario de 260 días, entre los nahuas, Quetzalcoatl es la deidad que personifica a Venus; entre los mayas, este planeta juega un significativo papel en la guerra y, entre los tarascos, cuenta con una gran variedad de advocaciones y se tiene como hijo del Sol y de la Luna y como deidad del sacrificio humano (1991: 194).

El pueblo tarasco forma parte de la cultura del occidente mesoamericano; probablemente es de origen chichimeca y, tras la caída de Tula, llega a las riberas septentrionales del lago Pátzcuaro, hacia el siglo XII d.C.; logra un amplio desarrollo metalúrgico, sobre todo, en los trabajos de cobre, bronce y tumbaga, y construye una sólida cultura lacustre que pervive hasta la conquista por los españoles, en el siglo XVI. Para algunos estudiosos, su religión posee claros tintes "monoteístas", pues se basa en el culto al fuego y a los astros, fundamentalmente, en la trinidad constituida por el Sol, la Luna y Venus, y que se sintetiza en Curicaueri, máxima divinidad, de donde se generan, a manera de advocaciones o representaciones, todas las otras deidades. Su lengua representa una de las grandes interrogantes del antiguo México, ya que no pertenece a ninguno de los troncos lingüísticos de Mesoamérica (González: 1991: 163).

La instancia narrativa asocia paulatinamente a Gabriel con lo indígena. En términos de la diégesis, él es un joven de 26 años, estudiante de la carrera de Medicina, quizás por eliminación de las otras dos profesiones liberales, ingeniería y derecho, que siguen sus hermanos 
Roberto y Álvaro; y quien, por vocación, "habría preferido ser literato" (Oreamuno 1994: 216). En el capítulo IX, Gabriel, en concordancia con sus facultades imaginativas y con sus aspiraciones de llegar a ser un buen médico, no sólo acepta la invitación que le extiende Elena para hacer juntos la autopsia o el desollamiento del cadáver de una india, el cual ella logra conseguir por medio de las propinas que le da al guarda del depósito de cadáveres, sino que escoge la piel y no los órganos, pues, considera que en el grano de ésta puede mirar "la casta y en el color de esa piel el pueblo de su nacimiento" (Oreamuno 1994: 128).

En cuanto a sus rasgos físicos y sus cualidades intelectuales, Gabriel es ampliamente caracterizado como un ávido lector, con gran capacidad de análisis y mucha sensibilidad; como un hombre diferente, con cara de huesos acusados, de nariz de hueso largo y de aletas anchas donde la piel parece tener sólo la función de cubrir, con el pelo negro y los ojos claros, a ratos grises, verdes o amarillos, según piense, sonría o se enoje; con los pómulos altos y estrechos, de boca pequeña, con el pecho alto y combado, los hombros anchos, las caderas estrechas y las piernas largas, y que de repente empieza a cambiar.

Así, recurre a gestos imprevisibles y a acciones incontroladas; sus gestos masculinos pierden fuerza y nitidez y, sobre todo, ya no se encuentra seguro de sus palabras ni de sus actitudes. Inclusive no sólo pasa de la frase concisa, "sabiamente moldeada" (1994: 310), según la narradora, a la interjección desordenada, al pensamiento inconcluso y a la cólera desatada, sino que tampoco sabe lo que dice y se queda a media frase; pero, ante esta dificultad o pérdida de la lengua española, él reactiva la conciencia de su identidad latinoamericana por medio de la memoria, específicamente, con el recuerdo de la palabra mencionada, a la cual quiere arrancar el secreto de su presencia; con el recuerdo de la muchacha morena, desconocida, procaz en el gesto, casera en el aroma, que "olía a tortilla" (1994: 327), y con los secretos rumores de su sangre.

La inscripción del significante Tzinzunzan aparece en el momento en que Gabriel, aparentemente enfermo, degradado, abstraído, entregado al sueño y que mastica la sopa o el líquido, estira la mano para alargar el plato, con el propósito de que Aurora le sirva más sopa. Precisamente, él recuerda la palabra cuando ve brillar la cuchara en su mano, es decir, al ver el utensilio que evoca el órgano de la palabra, la boca. A partir de aquí, se preocupa mucho por saber el significado de la palabra en comentario y por saber si se refiere a un animal, una flor, una casa, un verbo, un adjetivo, o un sustantivo; y al tenerla recurrentemente en su pensamiento, se molesta, se disgusta y le otorga una serie de calificativos, con lo cual pone de manifiesto las diversas tensiones y contradicciones ideológicas en el híbrido horizonte cultural latinoamericano: "Maldita palabreja" (Oreamuno 1994: 314), "la maldita" (316), "la palabreja infame" (317), "palabra estúpida (...) palabra necia (...) Suena como a vuelo; silba, parece que se aleja en la segunda sílaba y retorna en la tercera (...) suena bonito. Musical y dulce" (318), "Mi palabra familiar (...) Es una palabra horizontal, disparatada, loca, fina, iridiscente, movediza, pero siempre horizontal (...) Comienza a gustarme su dulce y melódico sonido" (325), "palabra salvaje y maldita" (327). La narradora básica también comparte los atributos de "necia" y de movimiento, puesto que expresa que "la palabra necia cada vez más grande, aleteaba" (336) sobre la agonía de Gabriel.

Paralelamente, Aurora se angustia por la salud mental de Gabriel, pues ella lo ha amado en su condición de hombre duro y hasta cruel, alto, fuerte y poderoso. Empero, él asegura que se encuentra bien y le reprocha que piense que ha enloquecido. Ante un pequeño espejo, él comprueba que todo está en su lugar y que nada se ha movido: los párpados, los 
ojos, la nariz y la boca; luego decide morir, es decir, suicidarse. Es necesario resaltar que tanto para Teresa como para la narradora básica morir significa regresar a la vida por medio del recuerdo, de la memoria: es un acto de autoconciencia, de evaluación del propio ser y de encuentro con el yo. Teresa, al igual que su hijo Gabriel, también quiso morir, asegura el médico que la examina.

Gabriel se contempla en el espejo en dos oportunidades: antes de recordar la palabra Tzinzunzan y antes de formularse la pregunta “¿Soy el mismo?” (Oreamuno 1994: 318). Súbitamente envejece, se mira sin vanidades, libre del orgullo que caracteriza a toda su familia y así llega al meollo, según la narradora básica, a la época de las conquistas, la más difícil de todas.

Por lo expuesto, es posible afirmar que la idea de la muerte no es lo que genera el texto, sino el concepto de transgresión, de tránsito, el cual se materializa en el espejo. Como diría Edmond Cros (1986: 270-9), éste polariza y concentra la semántica textual, o sea, el desdoblamiento de la conciencia de Gabriel, quien se proyecta como el objeto de su propia mirada y se desdobla en "Gabrieles", como refiere la narradora básica; la difracción del tiempo (presente y pasado), los juegos correlativos de los pronombres personales (yo-tú), la fragmentación de relato, la conjunción del nivel psíquico y del nivel exterior de la narración, la tensión entre la lengua y la religión mesoamericanas y la lengua y la religión hispánicas, y las modulaciones de la temática del reflejo: los recuerdos o la memoria y hasta la escritura. En suma, todo pasa por el mismo punto del foco espejo / conciencia, es decir, de la conquista de la propia identidad, personal y social, con lo cual se subvierte el concepto oficial de la conquista de América, es decir, de los otros por la adquisición de un territorio mediante operación de guerra.

Como se anotó, Tzinzunzan significa “donde está el colibrí”, significado que se presenta como un enigma para Gabriel; incluso él lo formula explícitamente por medio de la pregunta “¿Qué quiere decir esta palabra que recuerdo ahora?” (Oreamuno 1994: 314); por consiguiente, todas las calificaciones mencionadas en torno a la palabra operan también como dilaciones o propagaciones y la respuesta, circunscrita en los significantes Gabriel es un hombre / colibrí, constituye, a la vez, la respuesta a la pregunta que él se planteó ante el espejo “¿Soy el mismo?". El significante "colibrî", palabra americana de origen caribe, aparece connotativamente en los últimos seis renglones del capítulo XXII, el cual está conformado por 29 páginas, es decir, por ¿una inversión de 92 ?

La asimilación Gabriel / pájaro no sólo se reitera en diversas ocasiones, sino que asimismo aparece connotada tanto en la también reiterada mención a su larga y huesuda nariz con aletas anchas, la cual él hace topar con el cristal del espejo, precisamente, cuando se contempla y se interroga “¿Soy el mismo?”, como en algunas de las calificaciones que él da a la palabra Tzinzunzan, sobre todo, cuando refiere que suena como un vuelo y silba.

La asociación Gabriel / pájaro se pone de manifiesto después de que él ingiere las pastillas para suicidarse y se entrega al sueño, ¿a la hibernación?, que le permite la libertad de una evasión insospechada. Este estado configura el momento propicio para que reflexione en torno a su condición de "pedazo de hombre mutilado" (Oreamuno 1994: 327), a su tormentosa relación con Aurora, quien sólo puede amarlo mientras él sea un hombre distante, magnífico, libre, hermético, silencioso y soberbio, y, por lo tanto, no aceptaría que él se "le entregara dócilmente como un pajarillo con el ala quebrada entre el tibio calor de su mano, tembloroso y manso" (1994: 327 ), y sobre su certeza de que Aurora llegará a tenerlo para siempre sólido y entero. 
Conforme avanza el efecto de las pastillas y el consecuente estado fisiológico de disminución de las funciones metabólicas, Gabriel le solicita a Aurora que se tienda junto a él y le comenta que ella verá cómo se repetirán los golpes en la vena yugular, los cuales se harán "pequeños como corazón de niño, hasta que se hagan más pequeños como corazón de pájaro" (Oreamuno 1994: 332). También le pide que sienta su corazón de pajarito y le dice que ahora la ama como se ama al nido, a la tibieza, a la humedad y a la pluma, es decir, con un amor pequeño que ella puede coger en el hueco de la mano.

La asociación Gabriel / pájaro es ampliada por la narradora básica, quien describe el sueño de Gabriel como "ese sueño de criatura y pájaro" (Oreamuno 1994: 334), y refiere que la palabra Tzin...zun...zan aletea sobre la agonía del joven. Además, relata que éste se siente río y que llega hasta un pueblo de casas blancas, bordea la plaza y sigue avanzando hasta cerrar el cuadro de la plaza y ésta se convierte en una isla redonda. Dos grandes manchas móviles aletean y sus sombras cubren los árboles, y el pueblo se hace pequeño y desaparece. Empero, en el hueco de una mano tibia queda un pajarillo, "un colibrí minúsculo, de largo pico y enjoyadas alas” (1994: 337), el cual aletea como un corazón.

Así las cosas, es válido formular la siguiente pregunta: ¿esa mano es la de Aurora? Gabriel muere y ella inicia una nueva vida, precisamente, en la primavera, que es anunciada por el chiflido zigzagueante de un pajarillo y por los árboles, con sus piquitos castaños y algunas hojas adultas verdes como los ojos de la propia Aurora. Finalmente, ella también se planta ante el espejo, es decir, se proyecta como el objeto de su propia mirada y se desdobla, se llena de alegría y de esperanza, se siente libre, barre la casa, abre las ventanas, acomoda los muebles, se arregla prolijamente el peinado, tararea una canción, "se queda escuchando al fin con boca abierta y sonriente, el trinar de un pajarillo" (Oreamuno 1994: 362 ), ¿de Gabriel?, y espera a que se lleven el cuerpo humano muerto de su amante.

En suma, todas las consideraciones expuestas permiten referir a modo de conclusión que la compleja asociación Gabriel / Tzinzunzan constituye un rico y complejo proceso de delexicalización, pues La ruta de su evasión devuelve la plenitud sémica al significante tarasco, sometido a los caracteres latinos y a la correspondiente horizontalidad pero en continuo movimiento como el propio colibrí, para liberar los significados neutralizados por la lengua española, por el cristianismo y por el virreinato. Desde esta perspectiva, Yolanda Oreamuno, en tanto sujeto cultural, parece hacerse eco de las palabras posteriores de Carlos Fuentes, quien ha expresado: "Si no hay voluntad de lenguaje en una novela en América Latina, para mí esa novela no existe” (Fernández et al. 1977: 31).

\section{Bibliografía}

Amoretti H., María 1992. Diccionario de términos asociados en teoría literaria. San José: Editorial de la Universidad de Costa Rica.

Barthes, Roland 1980. S / Z. México: Siglo Veintiuno Editores, S.A.

Cooper, J. C. 2002. Diccionario de símbolos. México: Ediciones G. Gili, S.A. de C.V.

Cros, Edmond. 1986. Literatura, ideología y sociedad. Madrid: Editorial Gredos. 
1997. El sujeto cultural. Sociocrítica y psicoanálisis. Argentina: Ediciones Corregidor.

De Vallbona, Rima. 1972. Yolanda Oreamuno. San José: Ministerio de Cultura, Juventud y Deportes, Departamento de Publicaciones.

Fernández Moreno, César et al. 1977. América Latina en su literatura. México: Siglo Veintiuno Editores, S.A.

González Torres, Yolotl. 1991. Diccionario de Mitología y Religión de Mesoamérica. México: Ediciones Larousse.

León-Portilla, Miguel. 2003. Códices Los antiguos libros del nuevo mundo. México: Aguilar.

Macaya, Emilia. 1992. Cuando estalla el silencio. Para una lectura femenina de textos hispánicos. San José: Editorial de la Universidad de Costa Rica.

1997. Espíritu en carne altiva. San José: Editorial de la Universidad de Costa Rica.

Oreamuno, Yolanda. 1994. La ruta de su evasión. San José: Editorial Universitaria Centroamericana- EDUCA.

Pérez-Rioja, J.A. 1962. Diccionario de símbolos y mitos. Madrid: Ediciones Tecnos.

Picado Gómez, Manuel. 1979. "La ruta de su evasión” de Yolanda Oreamuno. San José: Editorial de la Universidad de Costa Rica.

Real Academia Española. 2001. Diccionario de la lengua española. Madrid: Editorial Espasa Calpe, S.A.

Rojas, Margarita y Flora Ovares. 1995. 100 años de literatura costarricense. San José: Farben Grupo Editorial Norma.

Soustelle, Jacques. 1956. La vida cotidiana de los aztecas en vísperas de la conquista. México: Fondo de Cultura Económica. 